\title{
Issues of Business Ethics in Domestic and International Businesses: A Critical Study
}

\author{
Aytaç Gökmen (Corresponding author) \\ Department International Trade, Çankaya University \\ Eskişehir Yolu, 29. Km., Yenimahalle 06810, Ankara, Turkey \\ E-mail: agokmen@cankaya.edu.tr \\ A. Turan Öztürk \\ Human Resources Department, Çankaya University \\ Eskişehir Yolu, 29. Km., Yenimahalle 06810, Ankara, Turkey \\ E-mail: atozturk@cankaya.edu.tr
}

Received: August 14, 2012

Accepted: September 2, 2012

Online Published: September 12, 2012

doi:10.5430/ijba.v3n5p82

URL: http://dx.doi.org/10.5430/ijba.v3n5p82

\begin{abstract}
Ethics is a significant issue in business both on the firm level and wider phases. Ethics indicate what is right and what is wrong in business branches also lead employees and stakeholders with moral values. Ethics is the basics for an impartial internal environment in an organization. An ethical climate constituted on fair foundations and lead by executives upholding ethical standards in the first instance tend to be more achieved when compared to other firms, since fair organizational internal environment motivates employees by satisfying their necessities, enhancing the organizational performance initially, then to bringing about industry and country wide developments. Thus, the aim of this paper is to review ethical management and corporate performance with a theoretical point of view, also with comprising the international business dimension of ethics and its significance for businesses resting on profound publications.
\end{abstract}

Keywords: Ethics, Codes, Management, Business, International business

\section{Introduction}

The possibility of ensuring the harmony between behavior and ethical values has been a great importance for a long time. The question in this process was how to alter the ethical values depending on various standards and deploy an ethical system that is conducive to development within a society and businesses. Fundamental approaches in developing ethical values are; justice that is to be impartial and rest on realities while operating an organization, human rights representing the equality among people, the optimization of sources which is the utilization of the sources in the best possible ways and focus on the development of the individual that is the initiation of social improvement. The principal of individualism does not involve the actions against morality to secure interests in the short or long term. A manager who can influence the attitude and behavior of its labors positively is to be taken as a role model of a just and earnest executive implementing the ethical standards. This type of progressive manager establishes the ethical standards and become an instigator of ethical climate in an organization. Organizations with universal ethical standards present a better performance, enjoy a positive image before the society and this would accommodate to establish stronger relations with the possible stakeholders in the long run (Aydin, 2003: 19-20; Burnaz et al., 2009; Rodriguez-Dominguez et al., 2009; Lamberton, Minor, 1995: 328; Certo, Certo, 2006: 50-56; McDaniel, Gitman, 2008: 45-50). Businesses are enhancing factors of industries and societies with respect to be being catalysts. Implementing ethical standards and values in these organizations would both facilitate the development of the business system and industries, as well as prompt state development as to inspire confidence on consumers leading to greater production. Therefore, the objective in this study is to review the issues mentioned above with regards to domestic and international business depending on profound publications. An additional purpose of this paper is to review the literature on ethics, compare it with a global point of view and attempt to differentiate the study from the previous ones with respect to the prevailing strength of international corporations and 
their influence on host markets as well as offer suggestions to converge the international businesses with local conditions to make the largest benefits for the indigenous and international parties.

\section{Theoretical Framework}

The study is focused on the subject of business ethics and the ethical climate constituted by the ethical management as well as its impact on the individual motivation and organization. Management is the activity of getting people all together to achieve an objective also with using the sources in a business effectively and efficiently. Management function in businesses involves planning, organizing, stuffing, leading and controlling. Within this process, human resource, technology, knowledge, natural sources, capital and entrepreneur are main inputs. Parallel to this concept, governance comprises the resolutions which deploy expectations, grant of power and verifying real performance. This concept comprises of management and leadership at once. Governance in a wider meaning, which is corporate governance is the system in which firms are managed and monitored. It includes regulation and market involvement, roles and relations between the management and subordinates, in the broadest meaning, the involvement of the business with shareholders, debt holders, creditors, suppliers, customers and all related parties (Rodriguez-Dominguez et al., 2009; Boone, Kurtz, 2011: 36-38; Certo, Certo, 2006: 4-10; Robbins, Decenzo, 2004: 6-10; Robbins, Coulter, 2002: 6-8; Daft, 2004: 384-386; Bailey, Spicer, 2007).

A well application of these concepts could be reinforced with executive and labor behaviors resting on morality and ethics. Morality (manner, individual properties and appropriate behavior) is the diversification of intentions, decisions and activities among the good and bad ones. Ethics which could also be named as moral philosophy comprises of systematizing, securing and suggesting notions on right and wrong behavior. Code of ethics or ethical codes are utilized by organizations to facilitate their members in understanding the difference between the right and wrong in the application of their decisions and while performing activities. Organizational ethics is the ethics of an institution and how the institution should respond to internal and external issues with the right dispositions (Burnaz, 2009; Helin, Sandström, 2008; Stohl et al., 2009; Svensson et al., 2009; Gaspar et al., 2006: 117-121; Boone, Kurtz, 2011: 44-48; Gomez-Mejia, Balkin, 2002: 60-68; Robbins, Decenzo, 2004: 309-314; Certo, Certo, 2006: 66-68).

Organizational ethics is closely related to organizational culture, values and ethical climate. Culture differentiates life in one group from life in another one, including mental contents, norms, institutions and other related properties. Organizational culture is the collective behavior of people who are components of organizations forming organizational values, vision, systems, language, norms, attitudes, behavior, belief and habits. Organizational culture is influential in effecting the course workers and groups interact among each other, with clients and stakeholders. An individual or cultural value is an exact or comparative ethical value that can be considered as an assumption of which is the basis for ethical action. Values and culture have profound impact on ethical climate in organizations which dwells on the ethical dimensions changing in the infrastructure of an organization. Ethical climate is the sum of values and culture in an organization designating what is right and wrong as well as akin to change by time. A value system in an organization is a set of stable ethical values whether individual or cultural and norms utilized for the purpose of ethical and organizational unity. Norms in a value system is the anticipated patterns of behaviors and beliefs expected by individuals to form a positive and effective organizational climate. All these concepts facilitate the motivation of employees that would lead positive outcomes for organizations. Motivation is a psychological trait that would lead an individual or related party to a desired action on a definite goal. Motivation in an organization is considerable to sustain an employee with occupational pleasure, individual satisfaction and positive contribution to the work place and its environment (Stohl et al., 2009; Burnaz et al., 2009; Rodriguez-Dominguez et al., 2009; Helin, Sandström, 2008; Svensson et al., 2009; Lamberton and Minor, 1986: 71; Gaspar et al., 2006: 229-234; Gomez-Mejia, Balkin, 2002: 108-112; Gibson et al., 2003: 229-230; Robbins, Coulter, 2002: 63-70, 127; Daft, 2004: 373-378).

\section{An Overview on Ethical Management, Its Impact on Individual and Organizational Performance and Motivation}

Organization having increasing performance and accomplishments always rest on the managerial talents of prospective leaders. Leadership is the process of social impact in which an individual can support others for the achievement of a joint objective. Leadership which is a sweeping factor in institutions constitutes a positive and stimulating ethical climate brings about behaviors and attitudes by employees conducive to developing performance both on the individual and organizational basis and contributes to the motivation of its stakeholders. For, a strong ethical climate in organizations positively influences managerial quality and institutional performance. Thus, the effect of ethical leadership on the performance of individuals and organization matters as a matter of fact that a constructive ethical climate would lead to performance development first in the firm level, then proceed through 
industry and economy wide achievement (Hunt et al., 1989; Wimbuch, Shepard, 1994; Burnaz et al., 2009; Weber, Seger, 2002; Griffin, Ebert, 1999: 212-215; Singhapakdi et al., 199; McDaniel, Gitman, 2008: 303-310).

Managers shall be role models and constitute an ethical atmosphere in organizations that is conducive to both individual and organizational development also with suggesting and instigating constructive attitudes in the organizational environment. Within an organizational environment stimulating positive behaviors and attitudes, ethical behaviors amount and unethical attitudes decline and cease to exist. In this process, leaders and executives perform the task of being forerunners of organization principles and processes taking the institution to an enhanced position (Kozlowski, Doherty, 1989; Burnaz et al., 2009; Rodriguez-Dominguez et al., 2009; McDaniel, Gitman, 2008: 161-163; Certo, Certo, 2006: 365-372; Gibson et al., 2003: 326).

Organizations are supposed to be achieved and demonstrate an ever increasing performance improvement to take the lead in their industries and acquire competitive advantage. A high level of performance could be best achieved with skillful and motivated employees. The conduct of business in organization in an ethical manner is of great importance to secure an increasing performance too. An organization functioning towards ethical standards would ensure impartial applications of business and recall a sense of justice and stimulate motivation among employees. Employees, with the sense of fair business applications would be motivated through the organizational goals, do their best to contribute to individual wellbeing and organizational development. Hence, firm level development is the inception of industrial and economic development too. An ethical climate in an institution would also facilitate to form stronger and long lasting ties with the stakeholders, thereby prolonging the firm life cycle as well (Marcoulides, Heck, 1993; Burnaz et al., 2009; Boone, Kurtz, 2011: 40-42; McDaniel, Gitman, 2008: 243-250).

Motivation is a crucial factor while executing a mission or a duty in an organization, for, a more motivated employee would be more enthusiastic than a less motivated employee and contribute more to organizational performance. Motivation is a comprehensive component in achieving organizational goals; because, employees equipped with the necessary skills and knowledge shall more actively perform duties parallel to executive achievements leading to the institution to a better phase and stronger position before its competitors. Though motivation is mostly regarded as an individual incident, it affects the institutional performance directly. An employee motivated through a positive ethical organizational climate and leadership could do much better than a less motivated employee and promote the organizational achievement also causing a wider development in the external environment of the organization as to be a positive instance and stimulator (Boone, Kurtz, 2011: 268-269; Helin, Sandström, 2008; Gomez-Mejia, Balkin, 2002: 300-306; Robbins, Decenzo, 2004: 279-281; Certo, Certo, 2006: 382-384;).

Motivation is an integral component of good leadership and managerial expertise. Therefore, motivation is a primary and sweeping issue for executives. Moreover, it is considerable to grasp the necessities and motivating factors of employees to instigate better arduous working aspirations in the institution and enhance the ethical climate in the organization by distributing the opportunities fairly. Employees struggle for equal chances, opportunities, enjoy expectations of impartial treat and appreciation of accomplishment. A leader or executive understanding and feeling the necessities and aspirations of its personnel would enhance the organizational performance by satisfying deficiencies and instigating the aspirations, thus contributing to organizational development and wider performance enhancement as a whole (Gaspar et al., 2006: 240-244; Stohl et al., 2009; Burnaz et al., 2009; Rodriguez-Dominguez et al., 2009; Robbins, Decenzo, 2004: 285-288; McDaniel, Gitman, 2008: 159-163; Robbins, Coulter, 2002: 432-436).

\section{Ethical Issues in International Business}

Business ethics is a prevailing subject in the field of both domestic and international business. Business ethics define the study of what is right, wrong, fair, reasonable and acceptable in the business world. Situations in the field of business towards ethical concerns have been in the rise for decades related to various problems, sectors and countries. In addition to this, as an aftermath of globalizing economies and markets as well as the increasing interdependencies of businesses, executives have begun to face issues related to ethical issues in markets that they do business. Yet, there are not any ubiquitously accepted rules every where in the globe. Thus, this complicates the adaptation and implementation of ethical rules and codes in international businesses. Therefore, ethical problems and controversies in international business ethics pose a great concern and require different point of views and solutions for each case. Besides, when the situation is considered from an economics and business point of view, business ethics is generally considered a subject contrary to business and economics issues rested on interests, upholding certain values in the first instance and based on a wide range of principles and its own philosophy (Burnaz et al., 2009; Choi et al., 2010).

The business operations in the $21^{\text {st }}$ century are ubiquitous and sweepingly global. Therefore, this immense scope of operations requires a deep understanding of culture, moral values and ethics in different parts of the world and 
markets. Moreover, a significant topic in the field of business is the acceptance possibility of the international business operations by local parties. This entails the reciprocal understanding and adaptation of ethical codes and rules by entire parities. From this point of view, the ethical standards unique to a host market and the standards of home market firm shall overlap at some point. Furthermore, the adoption of the ethical rules and moral values by a home country business is considerable to accommodate to consumer preferences and expectations; since, there could be widespread cultural and ethical divergences among home and host market parties. Additionally, the cultural, moral and ethical values could be alike in different countries; but, the implementation of these issues might vary. Therefore, the best course to adjust indigenous ethical and cultural standards is to adopt a contingency inclination on the cultural, morale, historical and individual basis rather than a universal point of view in order to influence ethical conduct positively (Tsalikis, Seaton, 2007; Tsalikis et al., 2008; Helin, Sandström, 2008).

Business ethics has always enjoyed a preferential position when compared to economic issues by scientists and academics. Therefore, the understanding and adoption of different ethical values in various host markets bear great significance. Besides, accommodating to indigenous values, culture and ethical rules entails the adoption of domestic knowledge and participation. This also requires concentrating on local application of ethics and focal understanding of social and psychological issues by home country executives. Henceforth, the adjustment to these issues by international businesses entails a deep understanding of details in international business ethics. Moreover, since every country does not pose same traits like the other ones, it is also substantial to grasp the differences between developed and developing country ethical applications. Today, developing countries represent about $80 \%$ of global population. Legal applications and uncertainty are sometimes great sources of concerns in international business operations. Therefore, while operating in a developing country, an international business has to take into consideration the domestic contexts, particularly the ones related to local culture, moral values as well as issues on technology transfer, innovation, intellectual property, finance and economics. It would be comprehensively beneficial for international businesses to search and make adoptions on these issues. Understanding business ethics also mattes in making decisions while administering a company both on the national and international basis since an ethical application may not accommodate the same practice in every market with respect to legal, political, cultural, human relations and many other regards. Even the applications in finance, management, accounting and economics may differ so much. Therefore, understanding the insights of ethics resulting from culture, moral values, education and legal instances are of great importance to be successful in the global competition arena by international businesses. (Choi et al., 2010; Chan et al. 2010; Bailey, Spicer, 2007).

Ethical values differentiate in every country and it is imperative for international businesses consider the important differences while conducting operations in host markets. For, the adoption of the discrepancies and conformities of ethics in host markets is a considerable asset for an achieved and coherent business structure while running company operations on the international basis. Host county culture and moral values are fundamental factors in determining the ethical perceptions regarding the new market as to estimate the mindsets of the potential clients since every nation has its own ethical standards. For instance, the ethical beliefs in the USA could be different than the ones in Greece; the moral values in Denmark are different than the ones in Jordan; and the ethical rules in India are much different than the ones in France. Therefore, one could indicate that the alternations in ethical perceptions or purposes across cultures and moral values are quite effective in decision making process of investments and focusing on the efforts of international business while deciding to enter a host market or not. There is a general conviction that the developed countries enjoy a higher level of ethical awareness when compared to the developing ones owing to the economic realities since the economically developed countries are supposed to have sound ethical standards to keep the process ever sustainable. Besides, transparency and the scope of ethical climate also matter. Businesses done in the most transparent and moral manners would inspire more confidence on both business and consumers thus expanding the volume of trade and economic power. Moral intensity is another significant factor for countries with deep moral intensity that are inclined to be more cognizant of ethical values when compared to low intense ones. This issue matters when an international business commits an act contrariwise to the moral values in a host market. Besides, consumers with dense moral intensity would constitute more press to be ethically focal than the less dense ones. The high return on investment and profitability are quite significant for international businesses, but, an immediate impact or magnitude of results of a business act or operation with respect to ethical values, understanding the social consensus on a behavior, the probable influence of an activity against the morale values and the lasting or uncertain impact of an unethical business application are substantial while making managerial decisions or investment plans in a host country. Therefore, it is indispensable to determine official and informal policies and procedures of an international business's ethical point of view to make itself acceptable in the public and its sector, since good adoption of ethics is an indicator of well done business. Additionally, the personnel working for an international firm shall be stimulated and authorized to take any action when witnessed an action against ethical 
values. This trend in an international business would inspire confidence in the public and make the institution a trustworthy one (Burnaz et al., 2009; Choi et al., 2010; Calderon-Cuadrado et al., 2009).

Deploying the manner of what is right and wrong in a business should be provided by establishing firm codes of ethics. The amounting dynamics with globalization and internationalization of businesses may appear as corruption, fraud, environmental situations and workplace mistreats. All these negative instances raised a global approach to corporate social responsibility for businesses especially for the ones operating in the international marketplace. Therefore, corporations indicating sound sense of legal, morale, social and legitimate tendencies for the consumers acquire competitive advantage over rivals and create and advantage in their business life cycles as an upward slope. Codes of ethics are official form of corporate fundamentals and measures to manage relations in organization on morale basis. Codes of ethics demonstrate the actual and future organizational and inter-organizational values and obligations for employees. Codes of ethics are indispensable for international institutions since 2008 Global Crisis reminded of people for its vitality. Thus, stating a possibly expected behavior for all employees and deploying them in codes of ethics is beneficial to anticipate similar behaviors from all workers. Ethics is a fundamental requirement when the financial scandals of 2008 are considered. Businesses in the international arena have immense investments that are worth billions of USDs and tainting the reputation of a global firm with simple ethical mistakes would not only hurt the employees and executives of that firm but the impact also includes the share holders and stakeholders as well. Ethical codes are clear documents of businesses aimed at constituting morale employee behavior and bring about change by making exact statements for expected behavior. Therefore, an international business adopting contemporary codes of ethics would constitute profession relationships rested on honesty and morale manners, comply with government laws and regulations, stimulate social responsibility and enhance managerial process and corporate culture. International businesses, by deploying such core issues within the corporation, would fortify the position of the firm before the public and accommodate transparency, thereby ensure a competitive status even in the face of domestic firms (Rodriguez-Dominguez et al., 2009; Stohl et al., 2009; Helin, Standström, 2008; Godos-Diez et al., 2011).

After the second millennium, the issues on environmental and occupational safety and accomplishing long term relationships with consumers, stakeholders and suppliers gained much significance. These issues have taken exclusive places in codes of ethics and embedded in legal codes of developed and most of the developing countries, also with taken into consideration by the society comprehensively. Besides, corporate social responsibility, the interests of share holders and stake holders emphasized in these clearly written documents as well as began to be adopted by executives and employees sweepingly. International firms pay exclusive importance to ethical codes and ethical applications since they operate in different cultures and legal environments. Complying with different cultures and laws require time and also facilitate the adoption of the international firm by locals too. Moreover, the content of ethical codes and applications shall bear product and service quality, consistency with domestic laws, preservation of nature, corporate social responsibility and transparency. These should be accommodated by international firms without violating the law and ethical values (Rodriguez-Dominguez et al., 2009; Stohl et al., 2009).

Ethical implementations of the $21^{\text {st }}$ century businesses possess a wide range of scope comprising corporate social responsibility, inter-organizational dynamics, public concerns, legal contexts and environmental issues. When the situation is considered from a global point of view, even the powerful corporations in the global business arena internationalize host market ethical rules for converging with local markets and highlight their positions in global competition. Since some global corporations have superior sources such as technology, human, finance and knowledge ascending the gross domestic product (GDP) of some sates, this surpassing power sometimes may lead to inappropriate and disproportionate impact on how the business is conducted in a host market, violating basic ethical values. Since large international corporations are mostly role models of their markets and being instances of right application of moral values is indispensable both to lead proper business applications in the market and surpass the ways to conduct business in the light of legitimate issues. By all means, contemporary institutions shall harmonize their policies with the law and morale values of host countries. They are supposed to form and adopt well defined codes of ethics in compliance with a multicultural extent, also with referring to the cultural differences well enough. In this process, new developments in communication and information technologies as well as global media applications facilitate the international community, states, nongovernmental organizations and international organizations to monitor corporations closer and shed light to improper developments immediately. Moreover, the web based applications enable consumers' access to ethical codes of business and convey their complaints directly to the corporation or state agencies. Corporations adopting and applying ethical codes responsibly are widely recognized as trustworthy and present their commitment to ethical conduct. A well defined ethical codes featuring corporate connection with consumers, employees, host governments, environmental issues, legal concerns and 
relations with stakeholders would present a clear corporate vision of an international business before a host country society, also with inspiring a sense of social responsibility and confidence (Stohl et al., 2009; Rodriguez-Dominguez et al., 2009; Svensson et al., 2009; Godos-Diez et al., 2011).

The issue of ethical managerial responsibility is also emphasized in the UN Global Compact profoundly. The UN Global Compact is a sweeping instance and pioneering document for complying with the ethical issues for global corporations. This document is also a source of ethical applications and solutions that could be denoted as (Note 1):

- Protecting and reinforcing universally accepted human rights,

- Not to involve in human rights violations,

- Upholding the right to collective bargaining,

- Prevention of forced and compulsory labor,

- Avoidance of child labor,

- Respect to occupational safety and remove of discrimination in employment opportunities,

- Taking necessary measures to prevent environment pollution,

- Adopting environmentally friendly policies,

- Stimulating the design and distribution of environmentally friendly technologies and equipments,

- Taking all legal and individual action against any for of corruption.

These items enumerated above are fundamental principles for international and domestic businesses to integrate their entities with ethical principles and reinforce morale values in their endeavors. Domestic businesses are easier to establish thanks to local awareness and knowledge. However, international investment is more complicated for the deficiency of local expertise and lack of knowledge. Therefore, while investing abroad, complying with ethical principles is a primarily important step to introduce a firm to a new host market. Besides, corporations upholding the ethical principles profoundly are adopted and respected in new host markets easily for possessing positive images. Eventually, a good and dignified inception in a new market is an effective way of corporate initiation for the mangers, employees, consumers and all related stakeholders.

\section{Conclusion}

Leaders and executives are substantial factors in constituting an ethical climate in organizations. Ethical principles lead an organization to its goals by determining what is good or bad in achieving its goals and fulfilling its tasks. An organization functioning in ethical standards would be immune of legal actions and risks and obtain a dignified and legitimate position before the public and its institutions. A good constituted ethical climate by leaders and executives in an organization (whether profit or non profit) should provide an impartial working environment for employees and a sense of trust for stakeholders. Employees would be more motivated through organizational objectives in a sound ethical business atmosphere. Especially, an employee whose necessities are satisfied in the best sense would be much more beneficial for its organizations and by all means, a firm level development shall bring about industry and country wide development eventually. Ethics in international business also matter substantially for every nation has its own ethical standards. An ethical adoption in one country may not bear the same importance or bring grave aftermaths along with it in another one. Thus, understanding and adopting ethical standards for each market and country is considerable to accomplish a high level of organization efficiency and effectiveness in the host country also having competitive advantage over rivals in the same industry as well as constituting a long lasting position in a host market, by acquiring a sense of trust from stakeholders that may lead a increasing volume of production, trade, sales and revenue.

\section{References}

Aydin, I. (2003). Managerial, Occupational and Organizational Ethics. Pegem Press, Ankara, Turkey.

Bailey, W., \& Spicer, A. (2007). When does national identity matter? Convergence and divergence in international business ethics, Academy of Management Journal, 50(6), 1462-1480.

Boone, L., \& Kurtz, D. (2011). Contemporary Business. Wiley, New Jersey.

Burnaz, S., Atakan, M.G.S., Topcu, Y.I., \& Singhapakdi, A. (2009). An Exploratory Cross-Cultural Analysis of Marketing Ethics: The Case of Turkish, Thai, and American Businesspeople. Journal of Business Ethics, 90(3), 371-382.

Calderon-Cuadrado, R. Alvarez-Arce, J.L. Rodriguez-Tejedo, \& I. Savetierra, S. (2009). "Ethics Hotlines" inTransnational Companies: A Comparative Study. Journal of Business Ethics, 88(1), 199-210. 
Chan, C.K. Fung, \& H.-G. Yau, J. (2010). Business Ethics Research: A Global Perspective. Journal of Business Ethics, 95, 39-53.

Choi, J.C., Kim, S.W., \& Kim, J. B. (2010). Globalizing Business Ethics Research and the Ethical Need to Include the Bottom of the Pyramid Countries: Redefining the Global Triad as Business Systems and Institutions. Journal of Business Ethics, 94, 299-306.

Certo, S., \& Certo, S.T. (2006). Modern Management. Prentice Hall, New Jersey.

Daft, R. (2004). Organization Theory and Design. Thomson South-Western, Ohio.

Gaspar, J., Bierman L., Kolari, J. Hise, R., Smith, M. Arreola-Risa, A., \& Welch, B. (2006). Introduction to Business. Houghton Miffin Company, Boston.

Gibson, J., Ivancevich, J., Donnelly, J., \& Konopaske, R. (2003). Organizations, Behavior Structure Process. McGraw-Hill, New York.

Godos-Diez, J.-L., Fernandez-Gago, R., \& Martinez-Campillo, A. (2011). How important are CEOs to CSR practices? An analysis of the mediating effect of the perceived role of ethics in social responsibility. Journal of Business Ethics, 98(4), 531-548.

Gomez-Mejia, L., \& Balkin, D. (2004). Management. McGraw-Hill, New York.

Griffin, R., \& Ebert, R. (1999). Business. Prentice Hall International, New Jersey.

Helin, S., \& Sandström, J. (2008). Codes, Ethics and Cross-Cultural Differences: Stories from the Implementation of a Corporate Code of Ethics in a MNC Subsidiary. Journal of Business Ethics, 82(2), 281-291.

Hunt, S., Wood, V., \& Chonko, L. (1989). Corporate Ethical Values and Organizational Commitment in Marketing. Journal of Marketing, 53, 79-90.

Kozlowski, S.W., \& Doherty, M.L. (1989). Integration of Climate and Leadership: Examination of a Neglected Issue. Journal of Marketing, 53, 79-90.

Lamberton, H., \& Minor, L. (1995). Human Relations: Strategies for Success. Chicago, Irwin.

Marcoulides, G.A., \& Heck, R.H. (1995). Human Relations: Strategies for Success. Chicago, Irwin.

McDaniel, C., \& Gitman, L. (2008). The Essential of the Future of Business. South-Western Cengage Learning, Australia.

Robbins, S., \& Coulter, M. (2002). Management. Prentice-Hall, New Jersey.

Robbins, S., \& Decenzo, D. (2004). Fundamentals of Management. Prentice Hall, New Jersey.

Rodriguez-Dominguez, L., Gallego-Alvarez, I., \& Garcia-Sanchez, I.M. (2009). Corporate Governance and Codes of Ethics. Journal of Business Ethics, 90(2), 187-202.

Singhapakdi, A., Kraft, K., Vitel, S.J., \& Rallapalli, K.C. (1995). The Perceived Importance of Ethics and Social Responsibility on Organizational Effectiveness: A Survey of Marketers. Journal of Academy of Marketing Science, 23(1), 49-56.

Sevensson, G., Wood, G., Singh, J., \& Callaghan, M. (2009). Implementation, communication and benefits of corporate codes of ethics: an international and longitudinal approach for Australia, Canada and Sweden. Business Ethics: A European Review, 18(4), 389-398.

Stohl, C., Stohl, M., \& Popova, L. (2009). A New Generation of Corporate Code of Ethics. Journal of Business Ethics, 90(4), 607-622.

Tsalikis, J., \& Seaton, B. (2007). The International Business Ethics Index: European Union. Journal of Business Ethics, 75, 229-238.

Tsalikis, J., Seaton, B., \& Li, T. (2008). The International Business Ethics Index: Asian Emerging Economies. Journal of Business Ethics, 80, 643-651.

Weber, J., \& Seger, J.E. (2002). Influences Upon Organizational Ethical Sub-climates: A Relocation Study of a Single Firm at Two Points in Time. Journal of Business Ethics, 41, 69-84.

Winbuch, J.C., \& Shepard, J.M. (1974). Towards an Understanding of Ethical Climate: Its Relationship to Ethical Behavior and Supervisory Influence. Journal of Business Ethics, 13, 637-647.

Note

Note 1. http://www.unglobalcompact.org/AboutTheGC/TheTenPrinciples/index.html _ the UN Global Compact (last accessed August 2012). 